Letters to the Editor

\title{
Thiuram Sulfides as a Reagent for the Solvent Extraction of Silver
}

\author{
Concepcion S. MendozA*, Satsuo Kamata ${ }^{* \dagger}$ and Kenichi Sodeyama** \\ * Department of Applied Chemistry and Chemical Engineering, Faculty of Engineering, Kagoshima University \\ Korimoto, Kagoshima 890, Japan \\ **Kagoshima Prefectural Institute of Industrial Technology, Oda Hayato, Aira-gun, Kagoshima 899-51, Japan
}

Keywords Silver ion, thiuram sulfides, solvent extraction, thiosulfate media

The dithiocarbamates which belong to the organosulfur compounds possess strong metal-binding properties and a capacity to form chelates with many metals as a non-selective complexing reagents. ${ }^{1}$ On the other hand, the use of thiuram sulfides which contain two moieties of dithiocarbamates would have an enhanced selectivity to metal ions due to the appropriate positions of their two dithiocarbamate groups. Further, the dithiocarbamate derivatives are less soluble in organic solvents, while these thiuram sulfides are soluble in organic solvents. Thiuram sulfides make a useful alternative to the dithiocarbamate derivatives, where it can be used to extract metal from the aqueous phase. Thiuram sulfides are also more stable in air and at room temperature, in solid or liquid form, than their parent compound, $N$-substituted dithiocarbamic acid, or their substituted ammonium or sodium salts. ${ }^{2-4}$

In this communication, the possibility of using thiuram sulfides for the solvent extraction of silver ion is reported. The extraction efficiencies of these thiuram sulfides towards silver ion are compared with $S, S^{\prime}-1,3$-propanediyl $O, O^{\prime}$-dibutyldithiocarbonate (PdBdTC), together with another commercial extractant, triisobutylphosphine sulfide (TIBPS). Thiuram sulfides are discussed as good extractants for silver ion in thiosulfate media.

\section{Experimental}

\section{Reagents}

Tetramethylthiuram monosulfide (TMTMS) was obtained from Nacalai Tesque, Inc. Tetramethylthiuram disulfide (TMTDS) and tetraethylthiuram disulfide (TETDS) were obtained from Tokyo Kasei Kogyo, while tetraisopropylthiuram disulfide (TiPTDS) was supplied by Aldrich Chemical Co., Inc. 1,1'-[Dithiodi(thiocarbonyl)]dipyrrolidine (DTDTCDPr) was synthesized by similar methods described previously. ${ }^{5}$ The product was purified by recrystallization and vacuum distillation.

$\dagger$ To whom correspondence should be addressed.

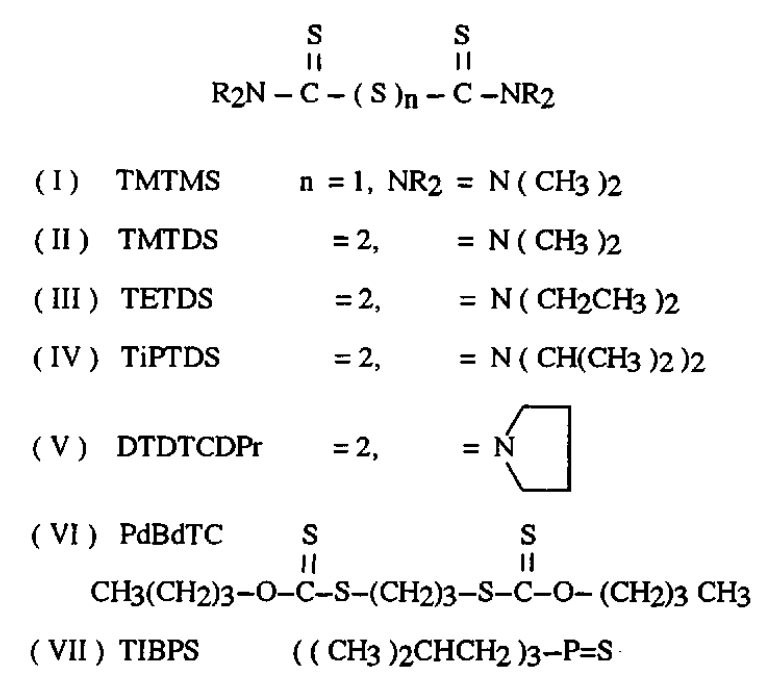

Fig. 1 Extractants used in this study.

Some of the physical characteristics and results of the elemental analysis for DTDTCDPr are as follows: white crystals, m.p. $132.0-133.0^{\circ} \mathrm{C}$, found: $\mathrm{C}=41.03, \mathrm{H}=5.50$, $\mathrm{N}=9.52 \%$, calcd. for $\mathrm{C}_{10} \mathrm{H}_{16} \mathrm{~N}_{2} \mathrm{~S}_{4}: \mathrm{C}=41.06, \mathrm{H}=5.51$, $\mathrm{N}=9.68 \% . \quad S, S^{\prime}$-1,3-propanediyl $\quad O, O^{\prime}$-dibutyldithiocarbonate (PdBdTC) was prepared and characterized as described previously. ${ }^{6}$ Triisobutylphosphine sulfide (TIBPS) was supplied by the American Cyanamid Company. The structures of these compounds are shown in Fig. 1.

Working solutions for metal ions were prepared by dissolving their nitrate or chloride salts in water. The diluent, 1,2-dichloroethane (DCE), was saturated with water before use. All other reagents used were of analytical grade. Distilled and deionized water is used throughout the experiments.

\section{Procedure}

The method of extraction is as follows: an aqueous solution $(10 \mathrm{ml})$ containing the metal salt or any other 
required reagents was shaken at a speed of 300 oscillations/min with a solution $(10 \mathrm{ml})$ of the extractant in DCE in a $50-\mathrm{ml}$ glass stoppered tube at $25^{\circ} \mathrm{C}$ for $1 \mathrm{~h}$. After phase separation, the metal concentrations in the aqueous phase were measured by atomic absorption spectrophotometry using AAS Model SAS 7500A (Seiko Instruments Inc.), and were calculated by mass balance of the metal content in the aqueous phase before and after equilibration.

\section{Results and Discussion}

The selective extraction of silver from thiosulfate solutions has not been exhaustively investigated because of the tight binding between silver and thiosulfate ions. Therefore, the extraction efficiencies of some thiuram sulfides together with other sulfur-containing compounds were evaluated for the extraction of silver from a perchlorate media and further tested in thiosulfate media.

The extractants considered in this study were highly selective for silver contained in perchlorate media, over the mentioned metals, as shown in Table 1. Extraction equilibrium was obtained at one-hour shaking time.

A high concentration $(0.1 \mathrm{M})$ of $\mathrm{NaClO}_{4}$ was used as source of the counter anion in the extraction of $\mathrm{Ag}^{+}$with thiuram sulfides. A $100 \%$ silver extraction and an effective phase separation was observed for most of the extractants. The effectiveness of thiuram sulfides towards silver extraction in the presence of interfering ions like $\mathrm{Cd}^{2+}$ and $\mathrm{Cu}^{2+}$ decreased in the order III $\simeq$ V $>$ II $>$ IV $>I$, excluding VI and VII. The extractability of silver with thiuram sulfides (I-IV) and the bis(dithiocarbonate) (VI), can be explained based on the relative fit of the ligand size to the silver ion radius (ring size effect). ${ }^{7-15}$ Thiuram sulfides possess the ideal Cshaped cavity to fit the $\mathrm{Ag}^{+}$, thus the selectivity for $\mathrm{Ag}^{+}$is higher. But PdBdTC (VI) is highly selective for $\mathrm{Ag}^{+}$ion over most of the base metals in perchlorate media. So the usefulness of PdBdTC as an extractant for $\mathrm{Ag}^{+}$from perchlorate media is better than thiuram sulfides, but a poor extractant for $\mathrm{Ag}^{+}$from thiosulfate media (Table 2). The thiocarbonyl function in PdBdTC also contributed to the mode of coordination and hence, selectivity of PdBdTC. The $\mathrm{C}-\mathrm{N}$ bond in the dithiocarbamate structure has a more polar character than the $\mathrm{C}-\mathrm{O}$ bond in dithiocarbonates, which enhances the reactivity of the dithiocarbamate molecule. ${ }^{17}$ Thus it may explain further why other metal ions in small amounts are coextracted with $\mathrm{Ag}^{+}$by thiuram sulfides. The values of silver extractability with thiuram sulfides are comparable with the result of a commercial extractant, TIBPS (VII) in perchlorate media.

In Fig. 2, plots of $\log D v s$. $\log [\mathrm{L}]$ for extractants $I$ and II are presented, where $D$ is the distribution ratio and [L] is the free ligand concentration after equilibration. In perchlorate medium, the plots gave slope values approximately equal to 2 , indicating that $1: 2$ silver-
Table 1 Extraction of metals from perchlorate media with the different extractants considered in this study

\begin{tabular}{cccccccc}
\hline & \multicolumn{7}{c}{ Metal extraction, \% } \\
\cline { 2 - 8 } & I & II & III & IV & V & VI & VII \\
\hline $\mathrm{Ag}^{+}$ & 100 & 100 & 100 & 100 & 100 & 96.1 & 100 \\
$\mathrm{Ca}^{2+}$ & 0 & 0 & 0 & 0 & 0 & - & - \\
$\mathrm{Cd}^{2+}$ & 16.2 & 1.0 & 1.0 & 1.6 & 0.9 & 0 & - \\
$\mathrm{Co}^{2+}$ & 3.3 & 0 & 0 & 0 & 0 & 0 & - \\
$\mathrm{Cr}^{3+}$ & 1.1 & 4.3 & 1.0 & 9.8 & 4.6 & 0 & - \\
$\mathrm{Cu}^{2+}$ & 79.8 & 31.6 & 6.3 & 44.2 & 3.4 & 0 & - \\
$\mathrm{Ni}^{2+}$ & 0 & 0 & 1.6 & 0 & 0 & 0 & - \\
$\mathrm{Pb}^{2+}$ & 10.8 & 2.0 & 6.5 & 39.7 & 2.4 & 0 & - \\
$\mathrm{Zn}^{2+}$ & 2.4 & 0 & 3.3 & 0 & 1.1 & 0 & - \\
\hline
\end{tabular}

$[$ Extractant $]=5.0 \times 10^{-3} \mathrm{M}$ in DCE; $\left[\mathrm{M}^{n+}\right]=1.0 \times 10^{-4} \mathrm{M}$ in $0.1 \mathrm{M} \mathrm{NaClO}_{4}$, shaking time $=1 \mathrm{~h}$.

$(-)$ means not analyzed.

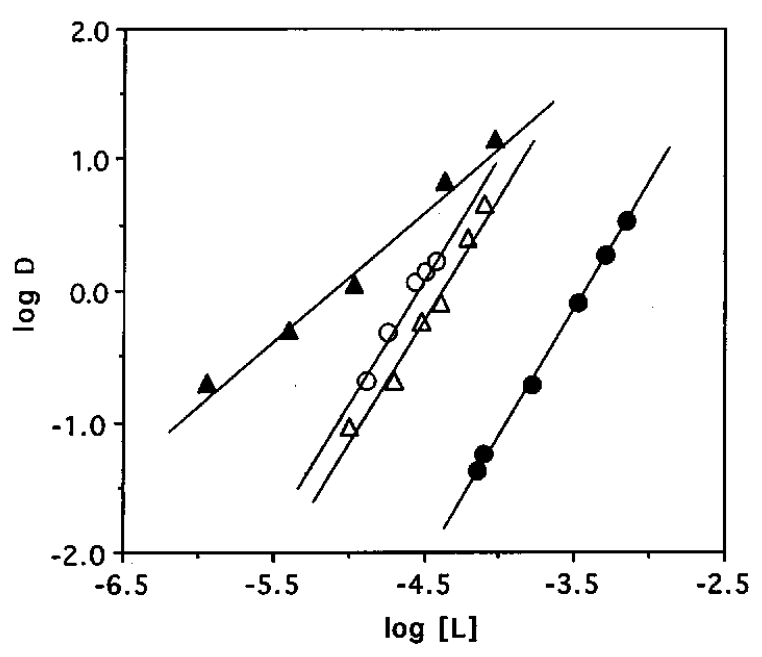

Fig. 2 Determination of silver-extractant complex stoichiometry by slope ratio method. [Extractant] $=0.8 \times 10^{-4}-5.0 \times$ $10^{-3} \mathrm{M}$ in DCE; $\left[\mathrm{Ag}^{+}\right]_{\text {perchlorate media }}=1.0 \times 10^{-4} \mathrm{M}$ in $1.0 \times 10^{-2}$ $\mathrm{M} \mathrm{NaClO}{ }_{4} ;\left[\mathrm{Ag}^{+}\right]_{\text {thiosulfate media }}=1.0 \times 10^{-4} \mathrm{M}$ in $1.0 \times 10^{-3} \mathrm{M}$ $\mathrm{Na}_{2} \mathrm{~S}_{2} \mathrm{O}_{3}$; shaking time $=1 \mathrm{~h}$. Slope values, in perchlorate media: $(O)$ TMTMS=2.03, $(\triangle)$ TMTDS=1.96; in thiosulfate media: (O) TMTMS $=1.93$, (A) TMTDS $=0.96$.

thiuram sulfide complexes were formed. The solvent extraction data in perchlorate media together with the NMR results of metal complexes of thiuram sulfides ${ }^{18}$ support the assumption that in these complexes the metal is coordinated to the sulfur atom of the thiuram sulfide with a tetrahedral structure.

The extractability of silver towards the different extractants in thiosulfate media are listed in Table 2. Lower silver extractabilities are observed for the extractants in thiosulfate media than in perchlorate media (Table 1) because stable silver complex, $\mathrm{Ag}\left(\mathrm{S}_{2} \mathrm{O}_{3}\right)_{2}{ }^{3-}$ is formed in the presence of thiosulfate ${ }^{16,19}$, possessing tight bonding between the silver and thiosulfate ions while a labile cationic silver exists in 
Table 2 Extractabilty of silver in thiosulfate medium with thiuram sulfides and other sulfur-containing extractants

\begin{tabular}{cc}
\hline Extractant & Ag extraction, \% \\
\hline I & 92.0 \\
II & 100 \\
III & 18.3 \\
IV & 18.7 \\
V & 84.6 \\
VI & 5.3 \\
VII & 3.6
\end{tabular}

$[$ Extractant $]=2.5 \times 10^{-3} \mathrm{M}$ in DCE; $\left[\mathrm{Ag}^{+}\right]=1.0 \times 10^{-4} \mathrm{M}$ in $4.4 \times 10^{-3} \mathrm{M} \mathrm{Na}_{2} \mathrm{~S}_{2} \mathrm{O}_{3}$; shaking time $=1 \mathrm{~h}$.

perchlorate media. The thiuram sulfides were further found to be better extractants for silver in thiosulfate media than the bis(dithiocarbonate) and thiophosphate systems, VI and VII respectively. The differences in silver selectivity between TMTMS (I) and TMTDS (II) is the manifestation of the difference in the number of sulfur atoms. TMTDS having a disulfide bond possesses an extensive resonance stability. The difference is also shown in the silver-ligand complex stoichiometries. Also presented in Fig. 2, are the plots of $\log D$ vs. $\log [\mathrm{L}]$ for I and II in thiosulfate media, giving slope values approximately equal to 2 and 1 , respectively. The values indicated that $1: 2 \mathrm{Ag}^{+}-\mathrm{TMTMS}$ and $1: 1 \mathrm{Ag}^{+}-$ TMTDS complexes were formed. Such results are consistent with the concepts of Saville ${ }^{21,22}$ regarding formation of complexes between silver ions and thiuram sulfides. TMTMS with $\mathrm{Ag}\left(\mathrm{S}_{2} \mathrm{O}_{3}\right)_{2}{ }^{3-}$ undergoes substitution and a further addition reaction; these do not need oxidation-reduction to take place. ${ }^{20,21}$ The mechanism is expected to explain the above results as follows:

$$
\begin{aligned}
& 2 \mathrm{R}_{2} \mathrm{NCSSSCNR}_{2}+\mathrm{Ag}\left(\mathrm{S}_{2} \mathrm{O}_{3}\right)_{2}{ }^{3-} \rightleftharpoons \\
& \quad\left[\mathrm{R}_{2} \mathrm{NCSSSCNR}_{2} \cdot \mathrm{Ag} \cdot \mathrm{R}_{2} \mathrm{NCSSSCNR}_{2}\right]^{+}+2 \mathrm{~S}_{2} \mathrm{O}_{3}{ }^{2-}
\end{aligned}
$$

In Eq. (1), the $\mathrm{NO}_{3}{ }^{-}$ion acts as the counter ion for the TMTMS-silver(I)-TMTMS complex in the organic phase. The coordinations of $\mathrm{Ag}^{+}$with TMTMS and TMTDS in perchlorate media are postulated to behave like they do in the thiosulfate media.

On the other hand, TMTDS is reduced to dithiocarbamate ions in the presence of silver ions, leading to the stable formation of tetrathionate ions and silver(I)dialkyldithiocarbamate such as: ${ }^{22}$

$$
\begin{array}{r}
\mathrm{R}_{2} \mathrm{NCS}_{2} \mathrm{~S}_{2} \mathrm{CNR}_{2}+\mathrm{Ag}\left(\mathrm{S}_{2} \mathrm{O}_{3}\right)_{2}{ }^{3-} \rightleftharpoons \\
{\left[\mathrm{R}_{2} \mathrm{NCS}_{2}-\mathrm{Ag}_{-} \mathrm{S}_{2} \mathrm{CNR}_{2}\right]^{-}+\mathrm{S}_{4} \mathrm{O}_{6}{ }^{2-}}
\end{array}
$$

The $\mathrm{Na}^{+}$ion as the counter cation permits the easy formation of the silver(I)-dialkyldithiocarbamate complex in the organic phase of Eq. (2).
Increasing the size of the alkyl groups in the dialkyldithiocarbamate should increase the lipophilic character in itself but also through the resultant increased inductive effect on the electron density of the dithiocarbamoyl moiety, resulting in reduced ionization constants. ${ }^{20}$ It should also decrease the electropositive character of the nitrogen atom and thus reduce the strength of the free acid. ${ }^{23}$ The effect is seen in extractants II - V; it shows that lengthening of the hydrocarbon chain reduces silver extractability. The high extractabilities of II and V suggest that it is the inductive effect rather than the mesomeric effect which determines the relative magnitude of total electron release in the series. ${ }^{24}$ The relative magnitude of electron release (inductive plus mesomeric) decreases in the order: methyl>pyrrolidinyl $>$ ethyl $\simeq$ isopropyl group. Independent work on $N, N$-dialkyldithiocarbamic acid derivatives showed the importance of the alkyl chain in the $N, N$-dialkyldithiocarbamate which decreases rapidly on ascending the homologous series. ${ }^{25-28}$ Complex formation between $\mathrm{Ag}^{+}$and extractants $\mathrm{VI}$ and VII is too small. Neither possesses the ability that the thiuram sulfides have to be reduced nor either undergo replacement reaction with thiosulfate ions.

Thus the extractability of silver with thiuram sulfides in thiosulfate medium decreased in the order: ID $>$ DV $>$ III $\simeq$ IV. Studies of the relationship between the degree of extraction versus the acidity of the aqueous phase indicated that maximum extraction of $\mathrm{Ag}^{+}$with TMTDS was achieved from pH 4.0 to 8.5. TMTDS, the most efficient extractant in thiosulfate media, was further tested on a analytical photographic fixing solution $\left(0.5 \mathrm{M} \mathrm{Na}_{2} \mathrm{~S}_{2} \mathrm{O}_{3}, 0.1 \mathrm{M} \mathrm{H}_{3} \mathrm{BO}_{3}, 0.05 \mathrm{M} \mathrm{CH}_{3} \mathrm{COONa}\right.$, $0.1 \mathrm{M} \mathrm{Na}_{2} \mathrm{SO}_{3} \cdot 7 \mathrm{H}_{2} \mathrm{O}, 0.1 \mathrm{M} \mathrm{CH}_{3} \mathrm{COOH}, 1 \mathrm{~g} / 1 \mathrm{Ag}$ ) which contains buffering, antioxidizing species and silver salts as well as thiosulfate. From this analytical fixing solution, a $100 \%$ silver recovery was obtained in $1 \mathrm{~h}$ shaking using a $0.01 \mathrm{M}$ TMTDS. A faster back-extraction stripping process with higher silver recovery using $\mathrm{HCl}$ from the $\operatorname{Ag}(\mathrm{I})-\mathrm{TMTDS}$ loaded organic layer was observed than with the back-stripping of silver with $\mathrm{NH}_{4} \mathrm{Cl}$ or $\mathrm{KNO}_{3}$ from silver(I)-amine ligand in the organic phase. ${ }^{29}$

Thiuram sulfides are an efficient extracting reagent for silver ion contained in thiosulfate and perchlorate media. The result for the extraction of silver from its thiosulfate complex can be further shown to be applicable to the recovery of silver from photographic fixing solutions using TMTDS extractant.

\section{References}

1. G. D. Thorn and R. A. Ludwig, "The Dithiocarbamates and Related Compounds", pp. 43-271, Elsevier Publishing Co., Amsterdam-New York, 1962.

2. A. E. Dimond, J. W. Heuberger and J. G. Horsfall, Phytopathology, 33, 1095 (1943).

3. J. W. Heuberger and T. F. Manns, Phytopathology, 33, 1113 (1943). 
4. G. D. Thorn, Can. J. Chem., 38, 2349 (1960).

5. S. Kamata, A. Bhale, Y. Fukunaga and H. Murata, Anal. Chem., 60, 2464 (1988).

6. D. A. Chowdhury, C. S. Mendoza and S. Kamata, Solv. Extr. Ion Exch., 112, 1051 (1994).

7. H. K. J. Frensdorff, J. Am. Chem. Soc., 93, 600 (1971).

8. C. J. Pederson and H. K. Frensdorff, Angew. Chem., Int. Ed., 11, 16 (1972).

9. J. J. Christensen, J. O. Hill and R. M. Izatt, Science [Washington, D. C.], 174, 459 (1971).

10. R. M. Izatt, D. J. Eatough and J. J. Christensen, Struct. Bonding [Berlin], 16, 161 (1973).

11. J. J. Christensen, D. J. Eatough and R. M. Izatt, Chem. Rev., 74, 351 (1974).

12. D. H. Busch, K. Farmery, V. Goedken, V. Katovoc, A. C. Melnyk, C. R. Sperate and N. Tokel, Adv. Chem. Ser., 1971, 52.

13. L. Y. Martin, L. J. DaHayes, L. J. Zompa and D. H. Busch, J. Am. Chem. Soc., 96, 4046 (1974).

14. D. D. Watkins, Jr., D. P. Reley, J. A. Stone and D. H. Busch, Inorg. Chem., 15, 387 (1976).

15. Y. Hung, L. Y. Martin, S. C. S. C. Jackels, A. M. Tait and D. H. Busch, Am. Chem. Soc., 99, 4029 (1977).

16. S. E. Livingstone, Quart. Rev. Chem. Soc., 19, 386 (1965).
17. J. Chatt, L. A. Duncanson and L. M. Venanzi, Nature [London], 177, 1042 (1956).

18. H. C. Brinhoff, A. M. Grotens and J. J. Steggerda, Recueil, 89, 11 (1970).

19. I. A. Shevchuk and E. E. Trekhos, J. Anal. Chem. USSR, 43, 441 (1988).

20. D. Coucouvanis, Prog. Inorg. Chem., 11, 233 (1970).

21. B. Saville, J. Chem. Soc., 1959, 2749.

22. B. Saville, J. Chem., Soc., 1962, 4062.

23. R. W. Greenlee, H. T. Kemp, R. S. Davidson and M. M. Baldwin, Preprint 71, Session I, of Nuclear Engineering and Science Conference, Chicago, 1958.

24. J. Links, Rec. Trav. Chim., 77, 1053 (1958).

25. M. C. Goldsworthy, E. L. Green and M. A. Smith, J. Agr. Res., 66, 277 (1943).

26. A. F. Parker-Rhodes, Ann. Appl. Bio., 30, 170 (1943).

27. H. L. Klopping and G. J. M. Van der Kerk, Rec. Trav. Chim., 70, 917 (1951).

28. T. Nakai and M. Okawara, Bull. Chem. Soc. Jpn., 43, 1864 (1970).

29. S. Strestrom, J. Photo. Sci., 39, 241 (1991).

(Received July 18, 1996)

(Accepted September 5, 1996) 